Research Paper

\title{
APPLYING TVDI BASED ON REMOTE SENSING DATA TO EVALU- ATE THE DROUGHT IN CU CHI DISTRICT
}

\author{
Tran Thi Thanh Dung1, Duong Thi Thuy Nga ${ }^{1}$
}

\author{
ARTICLE HISTORY \\ Received: March 20, 2020 Accepted: April 22, 2020 \\ Publish on: April 25, 2020
}

\section{ABSTRACT}

Drought is a constant threat to Vietnam which causes great damage to the economy as well as forest ecosystems. Due to the increasingly complex drought-related impacts, remote sensing technology with outstanding advantages compared to traditional research methods has been applied effectively in research, monitoring, and coping with drought. Normalized Difference Vegetation Index (NDVI) and Land Surface Temperature (LST) were calculated from Landsat imagery. The Temperature Vegetation Dryness Index (TVDI) with the combination of LST and NDVI index, was used as an indicator for drought risk assessment in $\mathrm{Cu}$ Chi District in 2005, 2010, 2015, and 2020. The results show a significant increase in dry areas between 20052010 and 2015-2020. On the other hand, the results of the TVDI index and mapping drought of $\mathrm{Cu}$ Chi district on February 13, 2005, February 11, 2010, January 24, 2015 and February 23, 2020 are a basis for risk assessment and drought monitoring.

Keywords: TVDI, Landsat 8, Drought, Cu Chi District

\section{Introduction}

Drought is a severe natural disaster around the world, which is a complex, and slow-onset phenomenon that affects more people than any other natural hazard and results in serious economic, social, and environmental impacts (Belal et al., 2012). Drought affects both developed and developing countries, but in different ways (Wardlow et al., 2012). In Vietnam, droughts occur across the country at different rates and times, causing enormous economic and social losses, especially for water sources and agricultural production. So that monitoring drought is very important. On the other hand, droughts often occur on a large-scale, so the monitoring and research by the traditional approaches for drought monitoring that uses ground-based data are laborious, difficult, and time-consuming (Prasad et al., 2007). In addition to recent advancements in the field of earth observation through different satellite based remote sensing sensors have provided researches continuous monitoring of soil moisture at a global scale, which can support drought assessment/monitoring.

Remote sensing can be applied on a large

\section{$\triangle$ TRAN THI THANH DUNG}

Corresponding author: trttdung@hcmus.edu.vn; dttnga@hcmus.edu.vn

${ }^{1}$ Ho Chi Minh City University of Science, Vietnam National University Ho Chi Minh City 
scale, all weather monitoring and multi-band working which are suitable for real-time monitoring on a large-scale. In recent years, with the development of multi-temporal and multi-spectral remote sensing technologies, the large amount of observational data has been achieved, which made it possible for real-time drought monitoring (Huang et al., 2011). Currently, methods of remote sensing for drought monitoring include thermal inertia, microwave remote sensing and the vegetation indices, etc. The Satellite-derived drought indicators calculated from vegetation index and other surface parameters other have been widely used to study droughts such as the Vegetation Condition Index (VCI), and Temperature Condition Index (TCI), TVDI. Kogan (1990, 1995) monitored drought by used the Vegetation Condition Index (VCI) and obtained good results from NOAA polar-orbiting satellite data. Moran et al. (1994) suggested Water Deficit Index (WDI) by extending Crop Water Stress Index (CWSI) to partly vegetation cover conditions. The Vegetation Temperature Condition Index (VTCI) is a near real-time approach of drought monitoring that is related to the NDVI and the LST changes developed by Wang et al. (2001). Sandholt et al. (2002) proposed a simplified soil surface dryness index based on an empirical parameter of the relationship between Ts and NDVI to detect the drought levels based on a large amount of data remote sensing called TVDI. Wang et al. (2004) evaluated the soil moisture status in China with the TVDI from March to May 2000 and found a significant negative linear correlation between the TVDI and measured soil moisture from NOAA polar-orbiting satellite data To assess drought in Shandong province in China Gao et al. (2011) integrated TVDI and regional water index (RWI) with Landsat TM / ETM + satellite imagery. Besides, Tao et al. (2011) applied GIS to monitor drought on Tongj in the land of Dafang district in Bijie prefecture of west Guizhou province. Son et al. (2012) illustrated the use of monthly MODIS NDVI and LST data to monitor agricultural drought along with Tropical Rainfall Measuring Mission (TRMM) data.

This article mainly studies drought monitoring in $\mathrm{Cu}$ Chi district based on TVDI using LANDSAT infrared thermal imaging material with a spatial resolution $(30 \mathrm{~m}-120 \mathrm{~m})$ to provide clearer information on changes in surface moisture content. In comparison with MODIS and NOAA/AVHRR images, it can be used effectively in researching and monitoring drought at the provincial level. The analysis results contribute to improving the method of identifying drought risk zoning to help local governments have an overview of droughts and make appropriate policies and planning of natural resources, contributing to mitigation. local disasters. Besides, the results can be used as useful references for research topics related to drought.

\section{Materials and Methods}

\subsection{Study area}

The study's objective is to assess the drought situation in $\mathrm{Cu}$ Chi district, Ho Chi Minh City, Viet Nam (Fig. 1). Cu Chi is a suburban district located to the northwest of Ho Chi Minh City, situated at the latitude of $10^{\circ} 53^{\prime} 00^{\prime \prime}$ to $11^{\circ} 10^{\prime} 00^{\prime}$ $\mathrm{N}$ and $106^{\circ} 22^{\prime} 00^{\prime \prime}$ to $106^{\circ} 40^{\prime} 00^{\prime \prime}$ E. Cu Chi District cover an area of 43,496 ha, with a natural area equaling to $20.74 \%$ of the city's area. The area has a typical monsoon tropical climate with two seasons: a dry season from November to April with low humidity and high evapotranspiration, and a rainy season from May to October with high humidity and low evapotranspiration (ADP, 2010). 


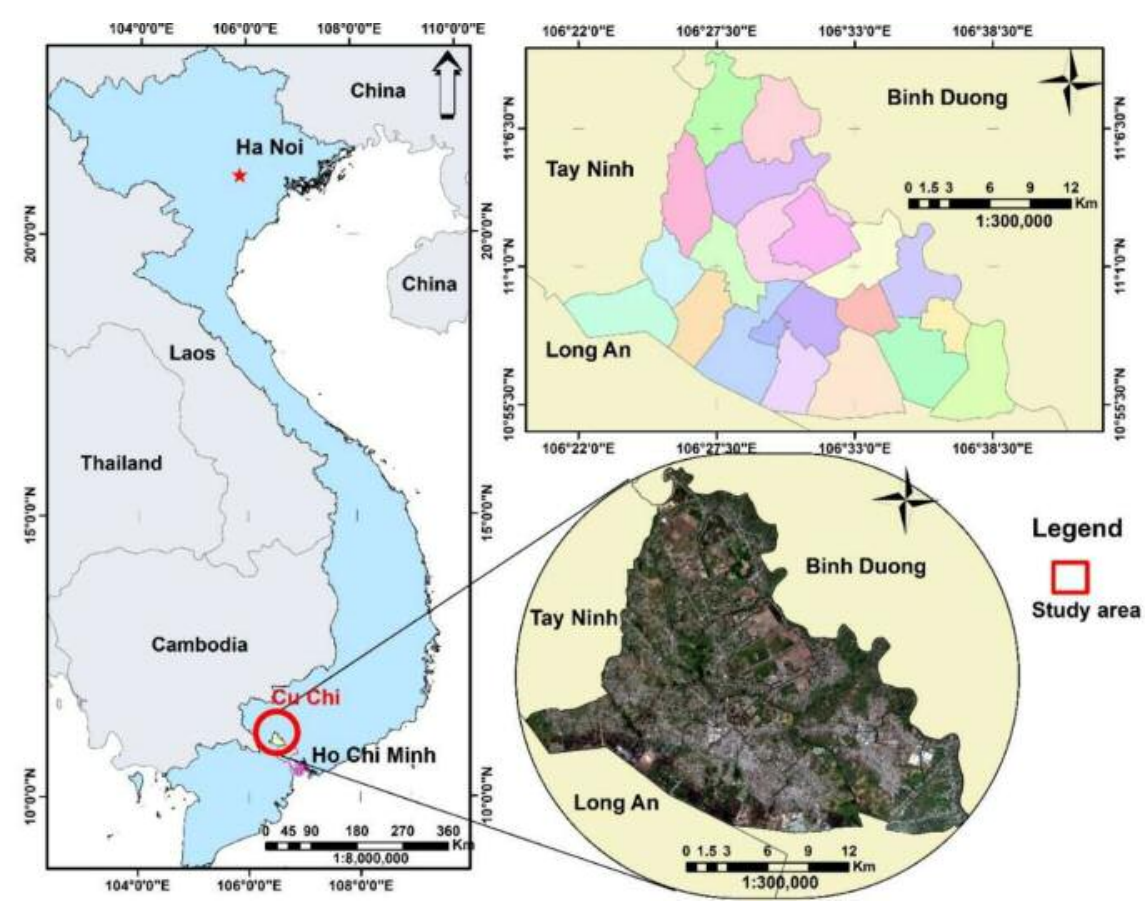

Fig. 1. Map of the pilot study area, Cu Chi District, Ho Chi Minh City, Central Viet Nam

\subsection{Data}

Landsat images (path 124/ row 052) were downloaded from the USGS data server (earthexplorer.usgs.gov) and used in this study. The first and second images were Landsat 5 Thematic Mapper (TM) acquired on 02/13/2005 and $02 / 11 / 2010$, respectively, while the third and fourth imagery were Landsat 8 (OLI/ TIRS) acquired on 01/24/2015 and 02/23/2020. Based on the study objectives, Landsat images were acquired during the dry season in $\mathrm{Cu}$ Chi district to best show land features, particularly, vegetation and soil moisture those concerning the occurrence of drought and to avoid overshadowing by too much vegetation (Ayad et al., 2020).

\subsection{Methodology}

In the method section, the research shows the processing of the Landsat data to estimate temporal trends of TDVI changes. Firstly, the Landsat datasets are pre-processed. The TVDI index was then calculated based on NDVI and LST.

\section{Satellite Image Processing}

To calculate the land surface temperature, the first step of the proposed work is to convert the DN (Digital Number) values of band Thermal infrared to at-sensor spectral radiance (Wm-2 m-
1). Landsat $5 \mathrm{TM}$ images can be converted to Top of Atmosphere (TOA) radiances using the following expression (1) (NASA, 2001):

$$
L_{\lambda}=\frac{\text { Lmax }-L m i}{\text { Qcalmax }-Q c a l m}(\text { Qcal }- \text { Qcalmin })+L \min
$$

where $\mathrm{L}_{\max }$ is the maximum radiance $\left(\mathrm{Wm}^{-2} \mathrm{sr}^{-}\right.$ $\left.{ }_{m}^{1} \mathrm{~m}^{-1}\right) ; \mathrm{L}_{\min }$ is the minimum radiance $\left(\mathrm{Wm}^{-2} \mathrm{Sr}^{-}\right.$ $\left.{ }_{m}^{1} \mathrm{~m}^{-1}\right)$; Q cal is the DN value of pixel; Qcalmax is the maximum $\mathrm{DN}$ value of pixels; $\mathrm{Q}_{\text {calmin }}$ is the minimum DN value of pixels.

To estimate the LST from the Landsat- 8 thermal infrared band data, DN of sensors were converted to spectral radiance using the following equation (2) (USGS, 2015):

$$
L_{\lambda}=\mathrm{M}_{\mathrm{L}} \cdot \mathrm{Qcal}+\mathrm{A}_{\mathrm{L}}
$$

where $L_{\lambda}$ is Spectral radiance (Watts $/\left(\mathrm{m}^{2 *}\right.$ $\left.\left.\operatorname{srad}^{*} \mu \mathrm{m}\right)\right) ; \mathrm{M}_{\mathrm{L}}$ is Radiance increasing scaling issue for the band (RADIANCE MULT _BAND_n from the metadata); $A_{L}$ is that the Radiance additive scaling issue for the band (RADIANCE_ADD_BAND_n from the metadata); $\mathrm{Q}_{\text {cal }}$ is Level one component worth in DN.

The next step is to convert the spectral radiance to TOA brightness temperature under the assumption of uniform emissivity by the fol- 
lowing equation (3) (USGS, 2015; Orhan et al., 2014):

$$
\mathrm{T}_{\mathrm{B}}=\frac{K_{2}}{\operatorname{Ln}\left(1+\frac{K_{1}}{L_{\lambda}}\right)}-273.15
$$

where $T_{B}$ is Top of Atmosphere Brightness Temperature; $\mathrm{L}_{\lambda}$ is Spectral radiance (Watts $/\left(\mathrm{m}^{2}\right.$ $\left.\left.{ }^{*} \mathrm{sr}^{*} \mu \mathrm{m}\right)\right) ; \mathrm{K}_{1}$ is Thermal conversion constant for the band (K1_CONSTANT_BAND_nfrom the metadata); K2 is Thermal conversion constant for the band (K2_CONSTANT_BAND_n from the metadata).

For obtaining the results in degrees Celsius, the radiation temperature is adjusted by minus $273.15^{\circ} \mathrm{C}$ (Xu et al., 2004; Orhan et al., 2014; Avdan and Jovanovska, 2016).

Calculation of Land Surface Temperature (LST or TS)

The Top of Atmosphere Brightness Temperature was converted to land surface temperature using the following equation (4) (Yuan et al., 2007; Rulinda et al., 2010):

$$
L S T=\frac{T_{B}}{1+\frac{\lambda \cdot T_{B}}{\rho} \cdot \ln \varepsilon}
$$

where $\lambda$ is the central band wavelength of emitted radiance; $\rho=\mathrm{h} * \mathrm{c} / \sigma(1.438 * 10-2 \mathrm{~m} * \mathrm{~K})$; $\sigma$ is the Boltzmann constant $\left(1.38^{*} 10-23 \mathrm{~J} / \mathrm{K}\right) ; \mathrm{h}$ is the Planck's constant $(6.626 * 10-34 \mathrm{~J} * \mathrm{~s})$; c is the light velocity $(2.998 * 108 \mathrm{~m} / \mathrm{s})$; $\varepsilon$ is the surface emissivity.

Accurate determination of surface temperature is restricted by associate degree correct data of surface emission. The emissivity of the surface is controlled by factors like water content, chemical composition, structure, and roughness (Snyder et al., 1998). It will be determined that the contribution of the assorted parts belongs to the pixels in their proportions. The link between LST and NDVI takes into consideration that vegetation and soils area unit the most surface protect the terrestrial element. The determination of the bottom emissivity is calculated not absolutely as prompt by Valor and Caselles (1996):

$$
\varepsilon=\varepsilon_{\mathrm{v}} \mathrm{Pv}+\varepsilon_{\mathrm{s}}(1-\mathrm{Pv})
$$

where $\varepsilon v$ is vegetation emissivity and $\varepsilon s$ is soil emissivity.

For the territory of Vietnam, several studies in Ho Chi Minh City have determined the $\varepsilon v$ and Es for LANDSAT images corresponding to 0.904 and 0.991 (Van et al., 2009).

$\mathrm{P}_{\mathrm{v}}$ is the Proportion of Vegetation in a pixel. $P_{v}$ is calculated according to Carlson and Ripley (1997) by the following equation (6) (Sobrino et al., 2004):

$$
P_{v}=\left(\frac{N D V I-N D V I_{\text {soil }}}{N D V I_{\text {veg }}-N D V I_{\text {soil }}}\right)^{2}
$$

\section{Calculation of Normalized Difference Vege-} tation Index

The "Normalized Difference Vegetation Index" (NDVI) was introduced by Tucker (1979) which is the most prominent vegetation index derived from remote-sensing (satellite) data used to identify and monitor vegetation. The value NDVI ranges between -1 to 1 with positive values for vegetation and negative values for non-vegetative areas. The NDVI is calculated by the following equation (7) (Myneni et al., 1995).

$$
N D V I=\frac{\rho_{N I \mathrm{R}}-\rho_{R E D}}{\rho_{N \mathrm{IR}}+\rho_{R E D}}
$$

where $\rho_{N I R}$ is the reflectance in Near-Infrared band; $\rho_{R E D}$ is the reflectance in Red band.

Calculation of Temperature Vegetation Dryness Index

The triangle method is based on an interpretation of the pixel distribution in the LST/NDVI feature space). Land surface temperature is affected by many factors such as surface thermal properties, net radiation, evapotranspiration, and vegetation coverage, hence there is no direct relationship between LST and soil water content. However, soil moisture is an important factor controlling vegetation canopy temperature and under certain vegetation coverage, soil moisture can indirectly affect canopy temperature. The Ts/NDVI feature space (Fig. 2) is used to illustrate the relationship between LST, soil moisture, and vegetation coverage. In the study of Price (1990) and Carlson et al. (1994), a scatter plot of remotely sensed surface temperature and 
a vegetation index often results in a triangular shape or a trapezoid shape in the study of Moran et al. (1994).

In this study using TVDI index is introduced by Sandholt et al. (2002), who have shown that the triangular feature space consists of a family of soil moisture isolines, which are also TVDI isolines, representing different degrees of aridity, and isolines closer to the upper boundary of the feature space represent pixels with low soil oisture. The horizontal line at the low limit in the Ts/NDVI feature space is called the wet edge (unlimited water availability) while the sloping line is called the dry edge (maximum evapotranspiration and limited water access) (shown in Figure 2). The TVDI can be calculated by the following equation (8) (Sandholt et al., 2002).

$$
\text { TVDI }=\frac{T s-\text { ssmin }}{a+b * N D V I-T s m}
$$

where $T_{\text {smin }}$ is the minimum surface temperature in the triangle, $\mathrm{T}_{\mathrm{s}}$ is the observed surface temperature at the given pixel, NDVI is the observed normalized difference vegetation index, $a$ and $b$ are parameters defining the dry edge modeled as a linear fit to data $\left(\mathrm{T}_{\operatorname{smax}}=\mathrm{a}+\mathrm{b}\right.$ *NDVI), and Tsmax is the maximum surface temperature observation for a given NDVI. The TVDI for a given pixel $\left(\mathrm{NDVI} / \mathrm{T}_{\mathrm{s}}\right)$ is estimated as the proportion between lines $\mathrm{M}$ and $\mathrm{N}$ (Fig. 2). $\mathrm{TVDI}=1$ on the dry side and TVDI $=0$ on the wet edge.

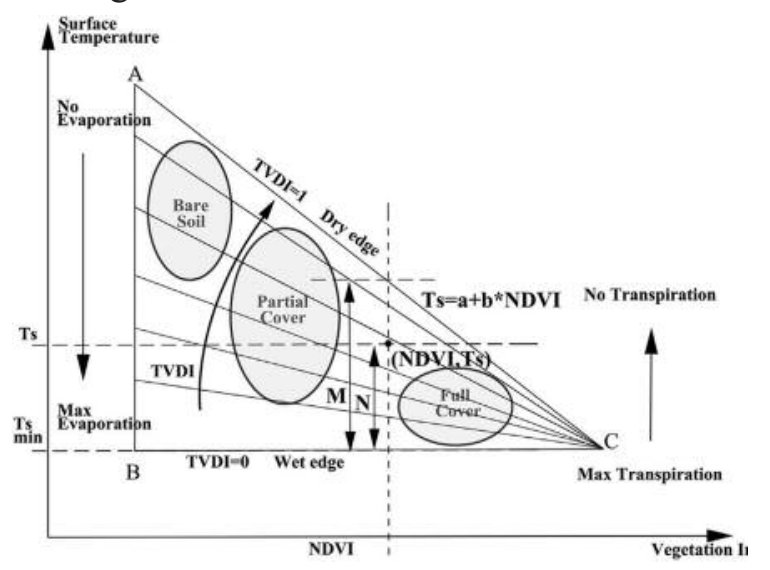

Fig. 2. Temperature Vegetation Dryness Index (Source: Liu et al., 2017)
TVDI mainly depends on the fitting equation of dry and wet edges of feature space, and TVDI is between $0-1$. The larger the TVDI value, the drier the soil and vice versa. Referring to a previous study on the division of drought-regime levels associated with the TVDI (Wang et al., 2004, Gao et al., 2011, Bao et al., 2013, Thuan et al., 2018). Based on this, this study will sample the partitioning criteria in subsequent analysis. The values of TVDI were classified into five intensity categories (Table 1).

Table 1. Drought categories for TVDI

\begin{tabular}{ll}
\hline TVDI & Categories \\
\hline $0-0.2$ & wet \\
$0.2-0.4$ & normal \\
$0.4-0.6$ & slight drought \\
$0.6-0.8$ & moderate drought \\
$0.8-1$ & severe drought \\
\hline
\end{tabular}

\section{Results and Discussions}

\subsection{Results of calculating LST index}

The NDVI index is the reflectance normalization difference index of RED and NIR band. NDVI is a general assessment of the green growth of plants, therefore, it can monitor changes in vegetation over time.

Band RED and Band NIR are respectively bands 3 and 4 with Landsat 5, bands 4 and 5 with Landsat 8. The NDVI index receives values from -1 to 1 . The low values of NDVI ( 0.1 and below) correspond to barren areas of rock, sand, or snow. The moderate values represent shrub and grassland ( 0.2 to 0.3$)$, whereas the high values indicate temperate and tropical rainforests $(0.6$ to 0.8) (NASA, 2013; Hien, 2013). The result of calculating NDVI is shown in Figs. 3a-3d.

Considering the emission factor, other conventional methods, usually use a mean for the whole vibration zone for the whole region. Therefore, Ts value after calculation is relatively accurate. Therefore, using the method of determining $\varepsilon$ using the NDVI, the TS value can be 
quickly calculated (Thuan et al., 2018). The re- sult of calculating LST is shown in Figs. 4a-4d.

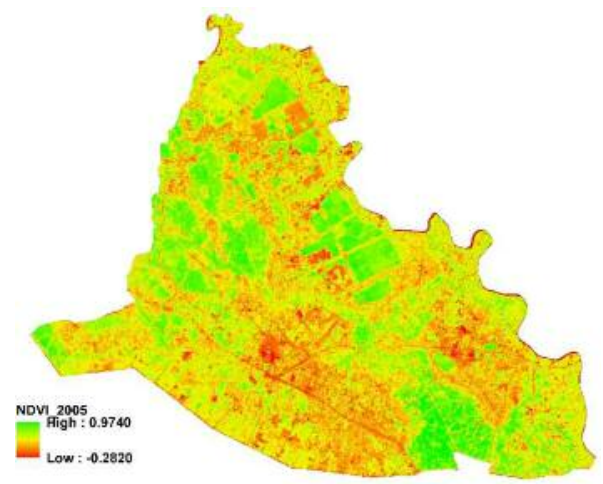

(a)

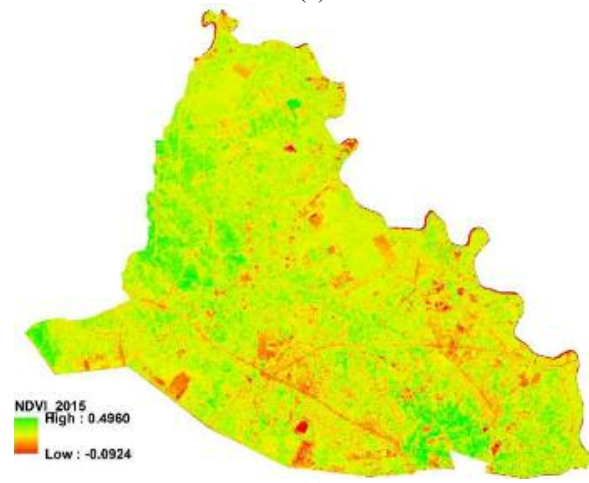

(c)

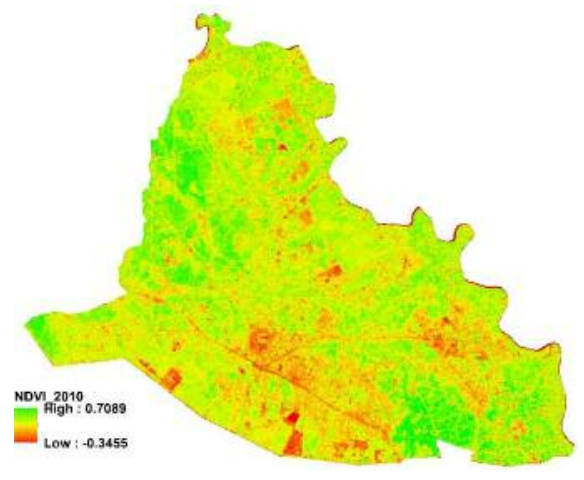

(b)

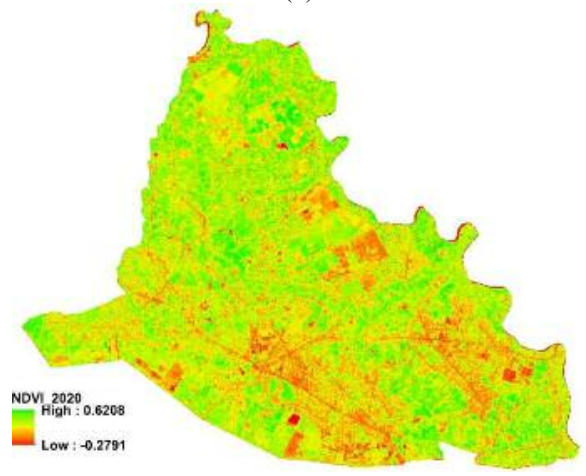

(d)

Fig. 3. NDVI results of $\mathrm{Cu}$ Chi district for Landsat images on 13 Feb 2005 (a), 11 Feb 2010 (b), 24 Jan 2015 (c) and 24 Feb 2020 (d)

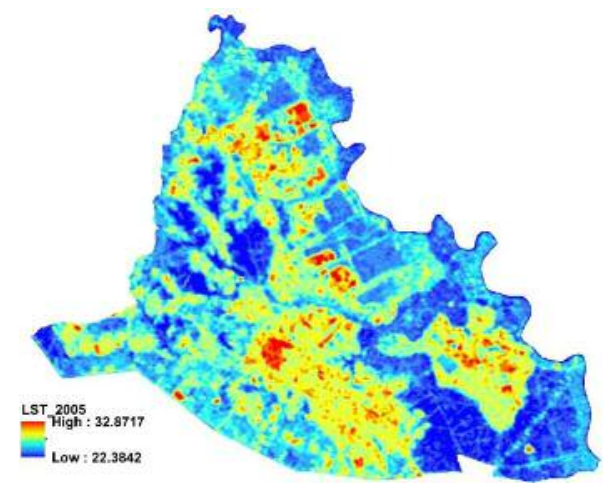

(a)

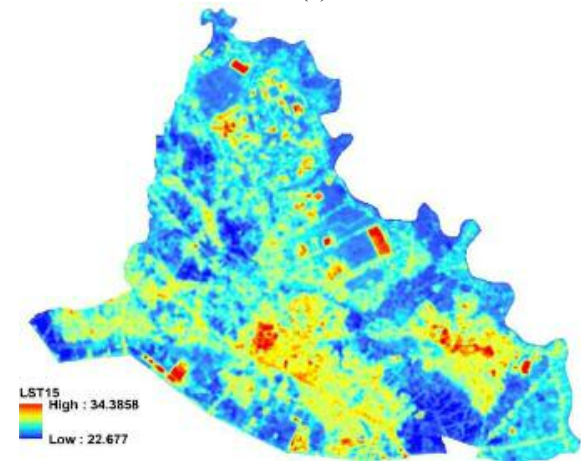

(c)

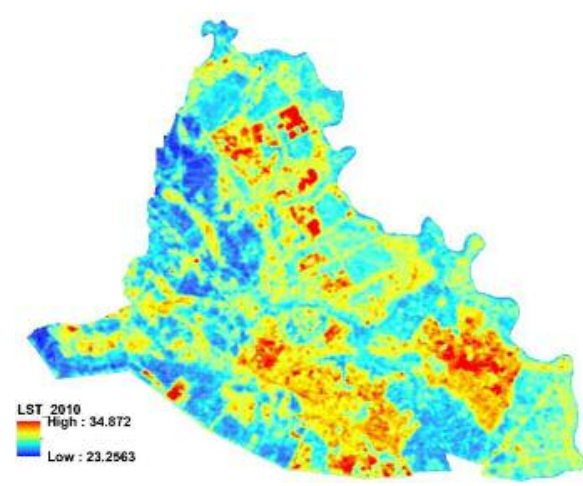

(b)

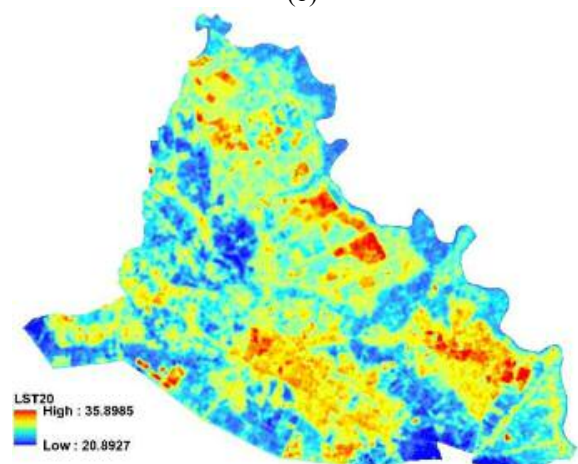

Fig. 4. LST results of $\mathrm{Cu}$ Chi district for Landsat images on $13 \mathrm{Feb} 2005$ (a), 11 Feb 2010 (b), 24 Jan 2015 (c) and 24 Feb 2020 (d) 


\subsection{Results of calculating TDVI index}

In the process of calculating TVDI, the dry and wet edges of the pixel can be determined according to the NDVI value of the pixel, and the value of the TVDI can be determined by the position of the surface temperature of the pixel in the feature space. The required NDVI data and its corresponding maximum land surface tem-

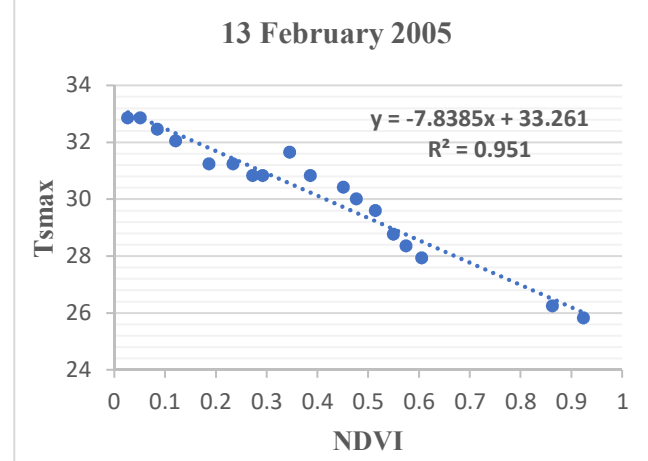

(a)

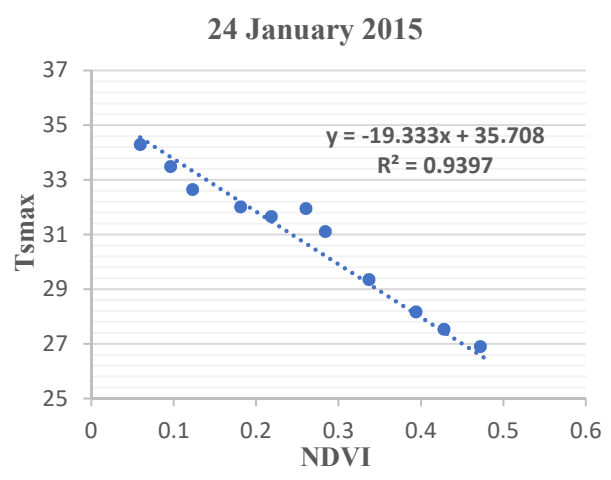

(c) perature are extracted from ArcGIS. Then use NDVI as the abscissa and $\mathrm{T}_{\text {smax }}$ were extracted for small intervals of NDVI, and the dry edge is estimated by linear regression (Fig. 5). The correlation is assessed by the correlation coefficient $\mathrm{R}^{2}$, if $\mathrm{R}^{2}$ the closer to 1 , the better the correlation.

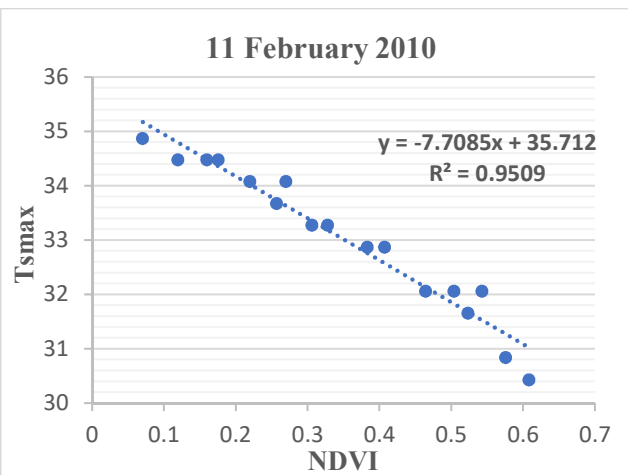

(b)

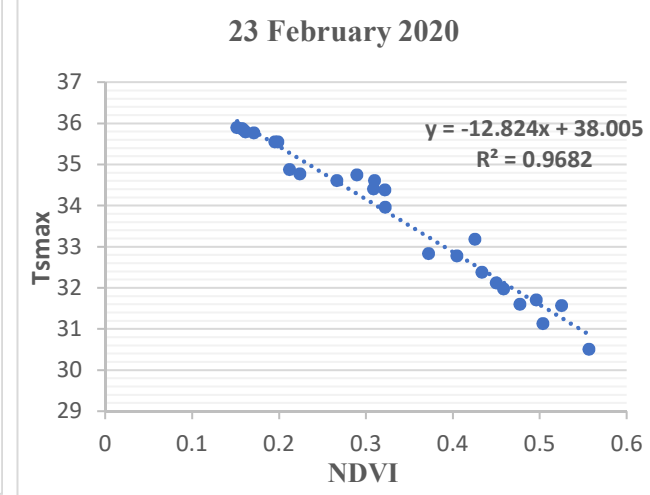

(d)

Fig. 5. Results of Tsmax "dry edge" determination for images on 13 Feb 2005 (a), 11 Feb 2010 (b), 24 Jan 2015(c) and 24 Feb 2020 (d) in Cu Chi district.

Tsmax "Dry edge" in the Ts/NDVI triangle space for images in 2005, 2010, 2015 and 2020 were determined as follows:

$$
\begin{aligned}
& \mathrm{T}_{\text {smax }}(2005)=-7.8385 \mathrm{xNDVI}+33.261 \\
& \mathrm{~T}_{\text {smax }}(2010)=-7.7085 \mathrm{xNDVI}+35.712 \\
& \mathrm{~T}_{\text {smax }}(2015)=-19.333 \mathrm{xNDVI}+35.708 \\
& \mathrm{~T}_{\text {smax }}(2020)=-12.824 \mathrm{xNDVI}+38.005
\end{aligned}
$$

$\mathrm{T}_{\text {smin }}$ was determined by taking the minimum temperature calculated from images in 2005 , 2010, 2015 and 2020. The results of TVDI of $\mathrm{Cu}$ Chi district from Landsat satellite data were shown in Figs. 6a-6d. A map of the relative drought level of $\mathrm{Cu}$ Chi district area based on the temperature vegetation dryness index (TVDI) is shown in Figs. 8a-8d.
The results of the calculation of the TVDI index with a resolution of $30 \mathrm{~m} \times 30 \mathrm{~m}$ show more clearly the areas affected by drought. The wet areas $(0-0.2)$ is represented by the dark green color, which is mainly the part containing water such as ponds, lakes, streams, or clouds in the unfiltered photograph. Areas with high vegetation cover, such as forests, are located in normal (0.2 -0.4), shown in green and moderate drought (0.4 - 0.6) in yellow, which indicates that this is very dry and easy to cause forest fire. It is necessary to take measures to prevent forest fires. Areas within the moderate and severe drought (0.6 - 1$)$ are shown in red and orange as the center of a densely populated district, town, or va- 
Tran Thi Thanh Dung et al./Vietnam Journal of Hydrometeorology, 2020 (04): 41-52

cant sandy area with little or no actual object. area by the limits of several years are presented The results of calculating the percentage of the in Table 2 and Fig. 7.

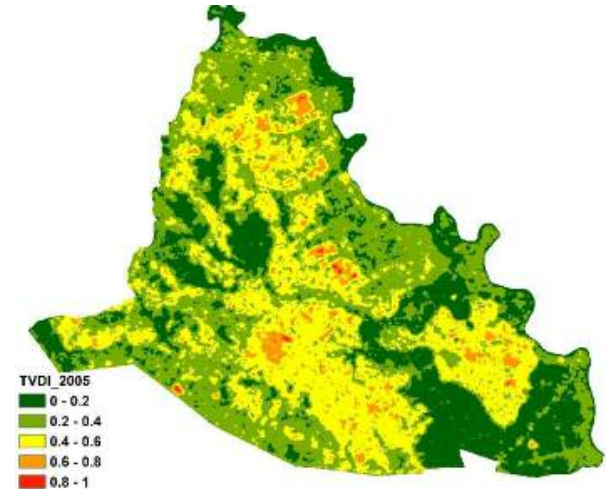

(a)

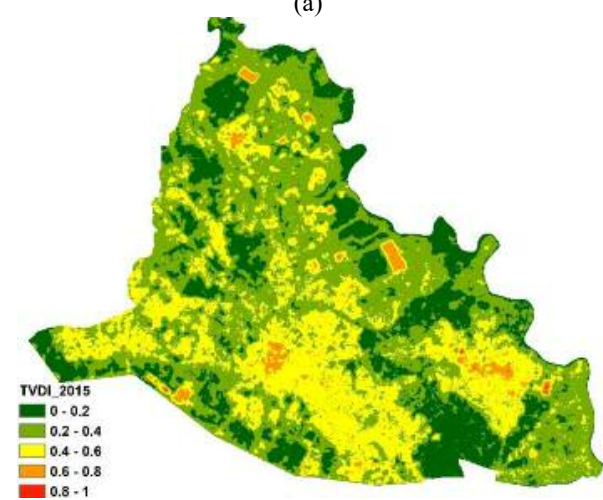

(c)

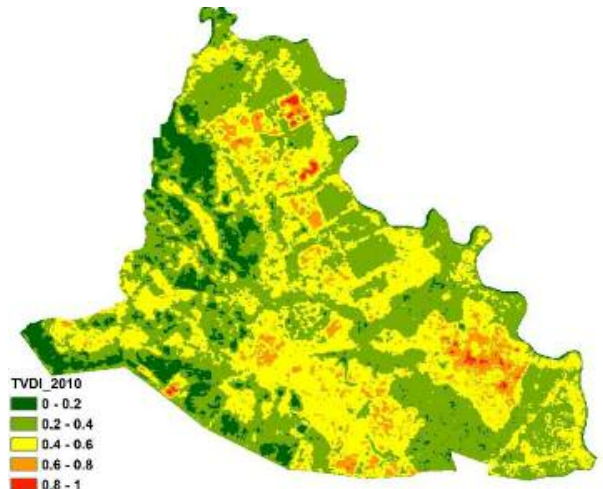

(b)

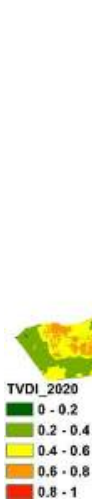

0.6 .0 .8
0.8 .1

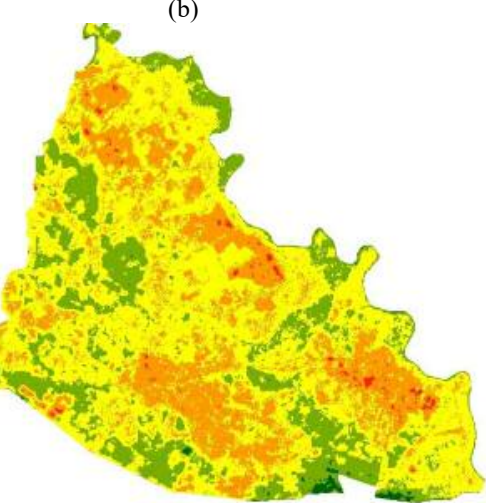

(d)

Fig. 6. Drought classification on 13 Feb 2005 (a), 11 Feb 2010 (b), 24 Jan 2015(c) and 24 Feb 2020 (d) in $\mathrm{Cu}$ Chi district.

Table 2. Area and Percentages of areas of TVDI levels in $\mathrm{Cu}$ Chi District in 2005, 2010, 2015 and 2020

\begin{tabular}{lcccccccc}
\hline \multirow{2}{*}{$\begin{array}{c}\text { Drought } \\
\text { categories }\end{array}$} & \multicolumn{2}{c}{$13 / 02 / 2005$} & \multicolumn{2}{c}{$11 / 02 / 2010$} & \multicolumn{2}{c}{$24 / 01 / 2015$} & \multicolumn{2}{c}{$23 / 02 / 2020$} \\
\cline { 2 - 8 } & Area (ha) & Ratio (\%) & $\begin{array}{c}\text { Area } \\
\text { (ha) }\end{array}$ & $\begin{array}{c}\text { Ratio } \\
(\%)\end{array}$ & $\begin{array}{c}\text { Area } \\
\text { (ha) }\end{array}$ & $\begin{array}{c}\text { Ratio } \\
(\%)\end{array}$ & $\begin{array}{c}\text { Area } \\
\text { (ha) }\end{array}$ & $\begin{array}{c}\text { Ratio } \\
(\%)\end{array}$ \\
\hline Wet & 10846.62 & 25.02 & 3942.27 & 9.09 & 9309.87 & 21.48 & 243.9 & 0.56 \\
Normal & 17723.25 & 40.89 & 20461.41 & 47.20 & 21056.58 & 48.58 & 8999.64 & 20.76 \\
Slight drought & 13038.84 & 30.08 & 16218.54 & 37.42 & 12004.92 & 27.70 & 23234.49 & 53.60 \\
Moderate drought & 1688.13 & 3.89 & 2542.95 & 5.87 & 958.68 & 2.21 & 10615.68 & 24.49 \\
Severe drought & 49.68 & 0.11 & 181.35 & 0.42 & 16.47 & 0.04 & 252.81 & 0.58 \\
\hline
\end{tabular}

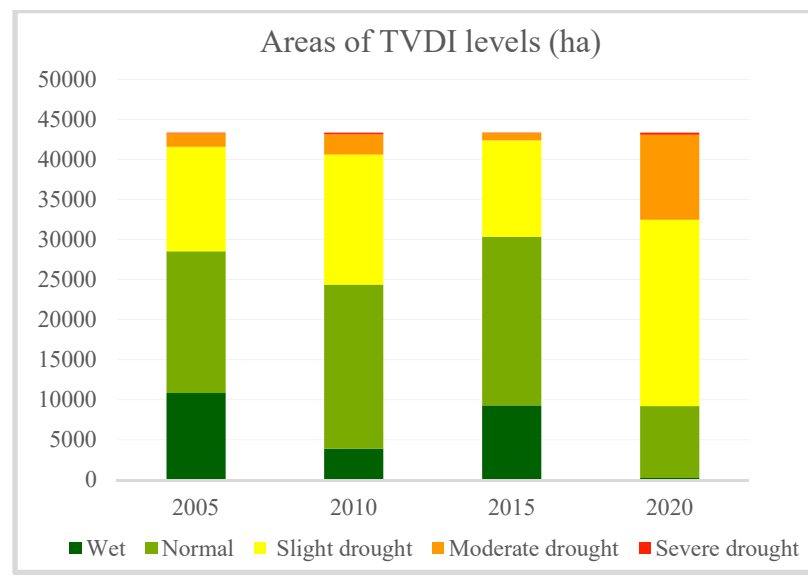

Fig. 7. A chart of areas of TVDI levels on 13 Feb 2005, 11 Feb 2010, 24 Jan 2015 and 24 Feb 2020 in $\mathrm{Cu}$ Chi District. 
The percentages of the areas at risk of severe drought increased sharply in 2010 compared to 2005 and 2020 compared to 2015 and concentrated mainly in areas of agricultural land and sand. In the years 2005, 2010, 2015 and 2020, the percentages of the areas with severe drought risk (corresponding to the TVDI index value greater than 0.8 ) all accounted for a very low rate

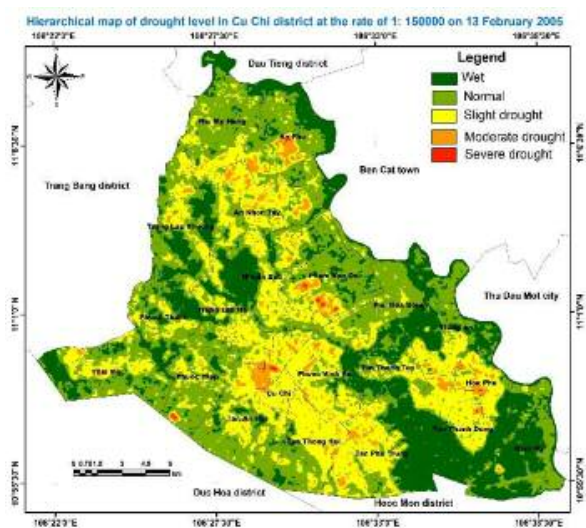

(a)

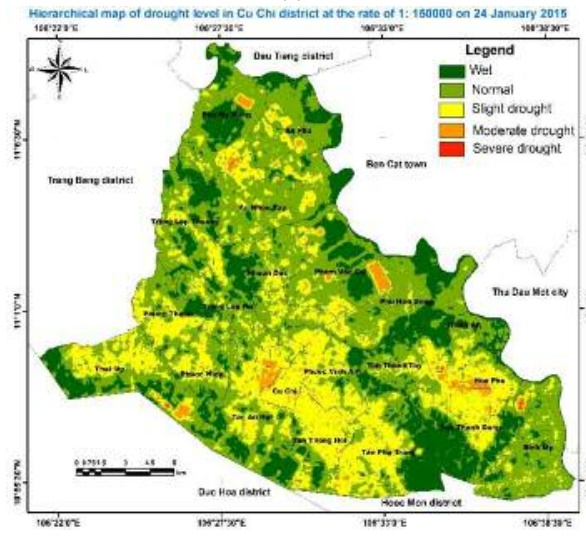

Fig. 8. Hierarchical map of drought level in Cu Chi District on $13 \stackrel{\text { (d) }}{\text { Feb }} 2005$ (a), 11 Feb 2010 (b),

$(0.11 \%, 0.42 \%, 0.04 \%$, and $0.58 \%)$. However, in the year 2020, The percentages of the areas at risk of severe drought and moderate drought have increased rapidly, accounting for $25.07 \%$ of the area. In general, drought in $\mathrm{Cu}$ Chi district tends to be more and more severe, affecting the living environment and production activities of the people.

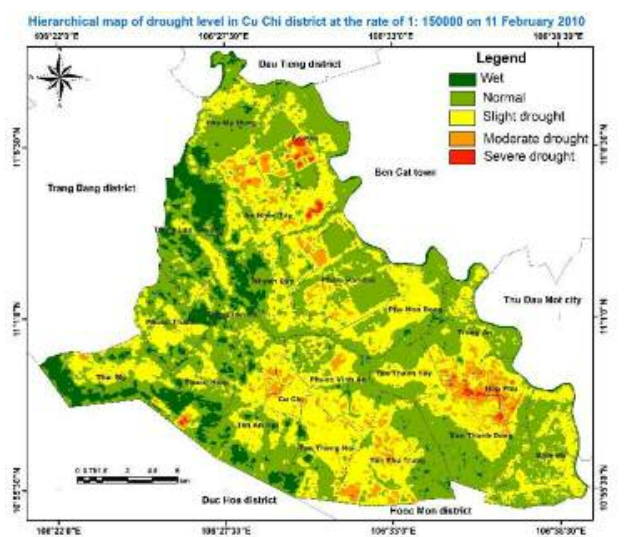

(b)

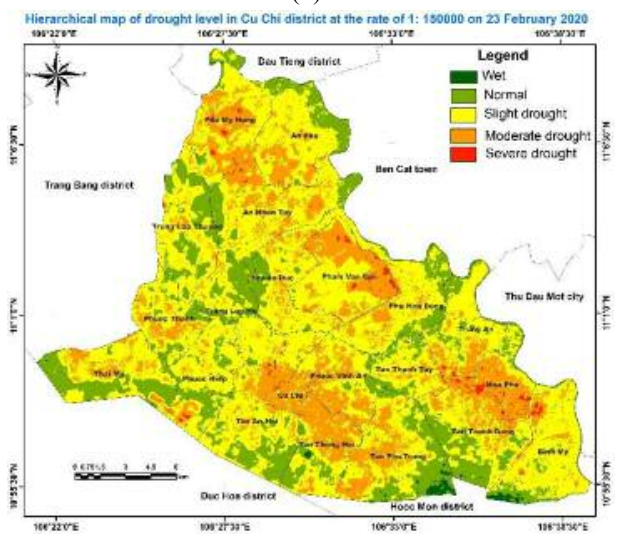

(d) 24 Jan 2015 (c) and 24 Feb 2020 (d).

On February 13, 2005, the area of the moderate drought and the severe drought were 1688.13 ha $(3.89 \%)$ and 49.68 ha $(0.11 \%)$ respectively. These areas mainly distribute in the residential area of $\mathrm{Cu}$ Chi Town, the agricultural land area in Pham Van Coi commune, the bare land in An Phu and An Nhon Tay commune, the landfill in Phuoc Hiep commune. The areas of the slight drought, about $30.08 \%$ (Table 2), and is dispersed throughout the district along the densely populated roads, the rest are non-drought and wet areas.

On February 11, 2010, the area of the severe drought areas increased from 131.32 ha to 181.35 ha $(0.42 \%)$ and the moderate drought areas increased to 2542.95 ha (5.87\%) compared to 2005 . The percentages of the slight drought areas increase to $7.34 \%$. These areas also distributed throughout $\mathrm{Cu}$ Chi district, while the wet areas decreased to 3942.27 ha, which fell by $15.93 \%$ compared to 2005.

On 24 January 2015, the wet area again increased to 9309.87 ha, accounting for $21.48 \%$. The area of the slight drought areas decreased to 120004.92 ha, accounting for $27.7 \%$ (fell by $9.72 \%$ compared to 2010 ), while the area of the 
moderate drought areas decreased to 958.68 ha $(2.21 \%)$, the percentages of the severe drought areas fell to $0.04 \%$. The area of drought has decreased due to the implementation of the Decision No. 05/2012/QD-UBND dated February 3, 2012 of the People's Committee of Ho Chi Minh City, approving the scheme on afforestation and greenery of the city in the period of 2011-2015, the area of forests and trees increased.

On February 23, 2020, the area of the moderate drought areas has increased rapidly in the period of 2015-2020 from 958.68 ha to 10615.68 ha $(24.49 \%)$, the area of the severe drought areas also increased to 252.81 ha $(0.58 \%)$ and increased by $0.54 \%$ compared to 2015 . These areas distributed throughout the region. The slight dry areas accounted for $53.60 \%$ of the area. The results from this research show that the areas with high temperatures, few plants or bare land are on the high level of drought. However, the drought level of other areas with lots of plant is not low. This reflects reality as in previous studies on TVDI, which is that although plant conditions exist, the lower water content also indicates high drought and is reflected by the high TVDI (Hung, 2014). As shown in Fig. 8. Thus, areas with vegetated areas with severe drought are important indicators to show the possibility of fire.

\section{Conclusion}

The results of the study have shown that the incidence of drought in $\mathrm{Cu}$ Chi district is increasing significantly from 2005 to 2020 , especially in the period 2015-2020 with heavy and medium arid areas.

From the results of the study, applying the correlation between plants and surface temperature can provide results for the drought risk of the study area. In addition to serving the fire warning, we focus on the areas with vegetations cover, but the drought is high (TVDI $>0.6$ ). These are areas where plants are in dry conditions for many days and lack of water, stems, and branches are easy to catch fire. Thereby is the basis for zoning warnings and preparing fire prevention plans timely.

The vegetation index as well as the surface temperature change according to seasons and weather conditions, so it is necessary to have survey results at different times to verify the accuracy of the drought index. In addition, temperature data calculated from images need to be combined with observed temperature data at measurement stations for comparison and inspection accuracy level when using.

\section{Acknowledgments}

The authors are grateful to VNUHCM-University of Science for supporting to do this research under Grant No. T2019-32.

\section{Conflicts of Interest}

The authors declare no conflict of interest.

\section{References}

1. Asian Development Bank 6 ADB Avenue, 2010. Mandaluyong City 1550 Metro Manila, Philippines, RPT10280. Available online: www.adb.org.

2. Avdan, U., Jovanovska, G., 2016. Algorithm for Automated Mapping of Land Surface Temperature Using LANDSAT 8 Satellite Data. Journal of Sensors, 2016:1-8. Doi: https://doi.org/10.1155/2016/1480307.

3. Ayad, M., Fadhil, A.Q., Qader, S.H., Wu, W., 2020. Drought Monitoring Using Spectral and Meteorological Based Indices Combination: A Case Study in Sulaimaniyah, Kurdistan Region of Iraq. In: Ayad M. Fadhil Al-Quraishi Abdelazim M. Negm (editors). Environmental Remote Sensing and GIS in Iraq. Springer Water, 377393. Doi: https://doi.org/10.1007/978-3-03021344-2.

4. Bao, Y., Gama, G., Gang, B., Yongmei, Alatengtuya, Yinshan and Husiletu, 2013. Monitoring of drought disaster in Xilin Guole grassland using TVDI model. Taylor \& Francis group, London, pp. 299-310. 
5. Belal, A.A., El-Ramady, H.R., Mohamed, E.S., Saleh, A.M., 2012. Drought risk assessment using remote sensing and GIS techniques. Arabian Journal of Geosciences, 7: 35-53. Doi: https://doi.org/10.1007/s12517-012-0707-2

6. Carlson, T.N., Gillies, R.R., Perry, E.M., 1994. A method to make use of thermal infrared temperature and NDVI measurements to infer surface soil water content and fractional vegetation cover. Remote Sensing Reviews, 9(1):161-173.

Doi: https://doi.org/10.1080/02757259409532220.

7. Carlson, T.N., Ripley, D.A., 1997. On the relation between NDVI, fractional vegetation cover, and leaf area index. Remote Sensing of Environment, 62(3): 241-252.

8. Department of the Interior U.S. Geological Survey (USGS), 2015. Landsat 8 (L8) Data User's Handbook. Version 1

9. Gao, Z.Q., Gao, W., Chang, N.B., 2011. Integrating temperature vegetation dryness index (TVDI) and regional water stress index (RWSI) for drought assessment with the aid of LANDSAT TM/ETM+ images. International Journal of Applied Earth Observation and Geoinformation, 13(3): 495-503. Doi: https://doi.org/10.1016/j.jag.2010.10.005

10. Hien, L.T.T., 2013. Application of the normalized difference vegetation index of Landsat imagery to assess the desertification in Binh Thuan Province. Vietnam Journal of Earth Sciences, 35(4): 357-363.

11. Huang, L., Guan, Q., Dong, Y., Zhang, D., Huang, W., Liang, D., 2011. Using Temperature Vegetation Drought Index for Monitoring Drought Based on Remote Sensing Data. Advanced Materials Research, 356-360 (2012): 2854-2859.

Doi: https://doi.org/10.4028/www.scientific.net/AM R.356-360.2854.

12. Hung, T.L., 2014. Studies of land surface temperature distribution using multispectral image Landsat. Vietnam journal of Earth sciences 36(1): 82-89

13. Kogan, F.N., 1990. Remote sensing of weather impacts on vegetation in non-homogeneous areas. International Journal of Remote Sensing, 11(8): 1405-1419.

14. Kogan, F.N., 1995. Droughts of the late 1980s in the United States as derived from NOAA polar-orbiting satellite data. Bulletin of the American Meteorological, 76(5): 655-668.

15. Liu, L., Liao, J., Chen, X., Zhou, G., Su, Y., Xiang, Z., Wang, Z., Liu, X., Li, Y., Wu, J., Xiong, X., Shao, H., 2017. The Microwave Temperature Vegetation Drought Index (MTVDI) based on AMSR-E brightness temperatures for long-term drought assessment across China (2003-2010). Remote Sensing of Environment, 199: 302-320. Doi: https://doi.org/10.1016/j.rse.2017.07.012.

16. Yuan, L., Heping, T., Hua, W., 2007. Dynamic drought monitoring in Guangxi using revised temperature vegetation dryness index. Wuhan University Journal of Natural sciences, 12(4): 663-668.

17. Moran, M.S., Clarke, T.R., Inoue, Y., Vidal, A., 1994. Estimating crop water deficit using the relation between surface-Air temperature and spectral vegetation index. Remote Sensing of Environment, 49(3): 246-263. Doi: https://doi.org/10.1016/0034-4257(94)90020-5

18. Myneni, R.B., Hall, F.G., Sellers, P.J., Marshak, A.L.,1995. The Interpretation of Spectral Vegetation Indexes. IEEE Transactions on Geoscience and Remote Sensing, 33(2): 481486.

Doi: https://doi.org/10.1109/TGRS.1995.8746029

19. NASA Earth Observatory, 2013. Available online: http://earthobservatory.nasa.gov/Features/MeasuringVegetation/measuring_vegetation_3.php.

20. National Aeronautics and Space Administration (NASA), 2001. Landsat 7 Science Data User's Handbook.

21. Orhan, O., Ekercin, S., Dadaser-Celik, F., 2014. Use of Landsat Land Surface Temperature and Vegetation Indices for Monitoring Drought in the Salt Lake Basin Area, Turkey. The Scientific World Journal, 2014, Article ID 142939, pp. 
11. Doi: https://doi.org/10.1155/2014/142939.

22. People's Committee of Ho Chi Minh City, Viet Nam (2012). Decision No. 05/2012/ QD-UBND dated February 3, 2012 of the People's Committee of Ho Chi Minh City approving the Project on afforestation and greenery of the city in the period of 2011-2015, http://www.congbao.hochiminhcity.gov.vn/cong-bao/vanban/quyet-dinh/so/05-2012-qd-ubnd/ngay/03-02 -2012/noi-dung/31922/32724.

23. Prasad, A.K., Singh, R.P., Tare, V., Kafatos, M., 2007. Use of vegetation index and meteorological index for the prediction of crop yield in India. International Journal of Remote Sensing, 28(23): 5207-5235. Doi: https://doi.org/10.1080/01431160601105843.

24. Price, J.C., 1990. Using spatial context in satellite data to infer regional scale evapotranspiration. IEEE Transactions on Geoscience and Remote Sensing, 28(5): 940-948.

25. Rulinda, C.M., Bijker, W., Stein, A., 2010. Image mining for drought monitoring in Eastern Africa using Meteosat SERVIRI data. International Journal of Applied Earth Observation and Geoinformation, 12(1): S63-S68.

26. Sandholt, I., Rasmussen, K., Andersen, J., 2002. A simple interpretation of the surface temperature/vegetation index space for assessment of surface moisture status. Journal of Remote Sensing of Environment, 79: 213-224.

27. Sobrino, J.A., Jimenez-Munoz, J.C., Paolini, L., 2004. Land surface temperature retrieval from LANDSAT TM 5. Remote Sensing of Environment, 90(4): 434-440.

28. Son, N.T., Chen, C.F., Chen, C.R., Chang, L.Y., Minh, V.Q., 2012. Monitoring agricultural drought in the Lower Mekong Basin using MODIS NDVI and land surface temperature data. International Journal of Applied Earth Observation and Geoinformation, 18: 417-427.

29. Snyder, W.C., Wan, Z., Zhang, Y., Feng, Y.Z., 1998. Classification based emissivity for land surface temperature measurement from space. International Journal of Remote Sensing, 19(14): 2753-2774.
30. Tao, J., Zhongfa, Z., Shui, C., 2011. Drought monitoring and analysing on typical Karst ecological fragile area based on GIS. Procedia Environmental Sciences, 10: 2091-2096.

31. Tucker, C.J., 1979. Red and photographic infrared linear combinations for monitoring vegetation.Remote Sensing of Environment, 8 (2), 127-150.

32. Thuan, N.D., Giang, N.Q., 2018. Assessment of the Occurrence of Drought in Luc Ngan District, Bac Giang Province Using Remote Sensing Technology. Vietnam Journal of Agricultural Sciences, 16(9): 820-829.

33. Valor, E., Caselles, V., 1996. Mapping land surface emissivity from NDVI. Application to European African and South American areas. Remote sensing of Environment, 57(3): 167184.

34. Van, T.T., Lan, H.T., Trung, L.V., 2009. Study on determination of urban surface temperature by thermal remote sensing method. Vietnam Journal of Earth Sciences, 31(2): 168177.

35. Wang, C., Qi, S., Niu, Z., Wang, J., 2004. Evaluating soil moisture status in China using the temperature vegetation dryness index (TVDI). Canadian Journal of Remote Sensing, 30(5): 671-679. Doi: https://doi.org/10.5589/m04-029.

36. Wang, P.X., Li, X.W., Gong, J.Y., Song, G.H., 2001. Vegetation temperature condition index and its application for drought monitoring. Proceedings of International Geoscience and Remote Sensing Symposium, Sydney, Australia, 9-14 July 2001, pp. 141-143.

37. Wardlow, B.D., Anderson, C.M., Verdin, J.P., 2012. Remote Sensing of Drought: Innovative Monitoring Approaches. CRC Press, First Eds.: pp. 484.

38. Xu, H.Q., Chen, B.Q., 2004. Remote sensing of the urban heat island and its changes in Xiamen City of SE China. Journal of Environmental Sciences, 16(2): 276-281. 